\title{
Simpósio de ensino de geologia no brasil
}

\author{
Pedro Wagner Gonçalves \\ Comissão Organizadora do EnsinoGeo09
}

Realizou-se no período de 1 a 5 de novembro de 2009 no Instituto de Geociências da USP, em São Paulo, o IV Simpósio Nacional O Ensino de Geologia no Brasil e o II Simpósio de Pesquisa em Ensino e História de Ciências da Terra (EnsinoGeo09). A Comissão Organizadora foi formada por membros do Instituto de Geociências, Faculdade de Educação e Instituto de Artes, Ciências e Humanidades (todos da USP) e do Departamento de Geociências Aplicadas ao Ensino do Instituto de Geociências da Unicamp. O evento ultrapassou o caráter nacional. Cerca de 160 participantes vieram de distintos estados brasileiros, bem como do exterior (Argentina, Inglaterra, Israel). O colega Pietro Corsi (Universidade de Oxford) ministrou a conferência magna sobre Charles Darwin, História da Geologia e evolução de espécies. A conferência final, proferida por Ricardo Latgé Milward de Azevedo (Petrobras) tratou das Perspectivas do petróleo do pré-sal e a formação dos geólogos. Um dos dias foi dedicado a atividades de campo e os participantes foram conduzidos a três viagens. A atividade de campo coordenada por Celso Dal Ré Carneiro (Unicamp) objetivou conhecer a geologia pré-cambriana do entorno do município de São Paulo, Grupo São Roque. A História da Geologia foi o tema principal da visita ao Jardim Botânico e Museu Paulista coordenada por Ermelinda Pataca (USP). A terceira percorreu o centro antigo da cidade de São Paulo para identificar a geologia de monumentos, conduzida por Denise de La Corte Bacci e Eliane Del Lama (USP). As palestras dedicadas à História da Geologia trataram tanto da história propriamente, quanto da divulgação do conhecimento científico. Kátia Mansur (DRM-RJ, Serviço Geológico do Rio de Janeiro) apresentou trabalho de caráter social, turístico e educativo de reconstituir os caminhos de Darwin no Rio de Janeiro; os trabalhos reconstituíram a expedição científica do Beagle e os estudos feitos pelo naturalista britânico no séculoXIX. Nelson Sanjad (Museu Paraense Emilio Goeldi) mostrou a história de como os gabinetes dos naturalistas se tornaram museus de História Natural. Ermelinda Pataca (USP) explorou os vínculos entre Portugal e a América Portuguesa por meio das expedições científicas patrocinadas pelo rei. Silvia Figueirôa (Unicamp) revelou a contribuição de Alberto Paes Leme para o conhecimento geológico brasileiro no início do século XX. Paulo Boggiani (USP), Presidente da Comissão Organizadora do EnsinoGeo09, na mesa redonda de Formação de Professores de Geociências, apresentou o curso de Licenciatura em Ciências da Terra da USP. A sessão discutiu diferentes propostas para formar professores de Ciências com mais conteúdo geológico. Foi assinalada a ausência de disciplina específica de Geociências na grade curricular do ensino básico. Ivan A. do Amaral (Unicamp) assinalou a necessidade de recordarmos as flutuações de maior e menor destaque das Ciências da Terra na formação de professores de Ciências nas últimas dezenas de anos. Nir Orion (Instituto de Ciências Weizmann, Israel) mostrou que Ciência do Sistema Terra pode organizar o currículo de ciências do ensino básico. Orion assinalou que o entendimento sistêmico do ambiente contribui para formar habilidades cognitivas essenciais à alfabetização científica e ambiental. Hector Lacreu (Universidade Nacional de San Luis, Argentina) de certo modo complementou o argumento, ao enfatizar a importância dos conteúdos geológicos para formação política dos cidadãos. Defendeu que esse conhecimento contribuiria para tornálos mais conscientes, ao tomar decisões sobre problemas ambientais. A Educação Ambiental mereceu especial atenção dentro do EnsinoGeo09. O tema foi contemplado por palestras de convidados e trabalhos espontaneamente enviados. Joseane Santos e Rosely Imbernon descreveram ideias de ambiente de estudantes de Educação Ambiental. Os autores revelam que, de fato, há certa confusão e falta de delimitação no pensamento dos alunos. Os 73 trabalhos enviados foram reunidos nas Atas do EnsinoGeo09. Os trabalhos incluem diversos aspectos de pesquisas e experiências de formação de professores, História da Geologia, estratégias de ensino para diferentes graus de escolaridade. Os debates ocorridos conduziram à sugestão de que o próximo EnsinoGeo, em 2011, seja realizado no Rio de Janeiro. 